\title{
Integrative species delimitation based on COI, ITS, and morphological evidence illustrates a unique evolutionary history of the genus Paracercion (Odonata: Coenagrionidae)
}

\author{
Haiguang Zhang ${ }^{1}$, Xin Ning ${ }^{2,3}$, Xin Yu ${ }^{\text {Corresp., }}{ }^{4}$, Wenjun Bu ${ }^{2}$ \\ ${ }^{1}$ College of Life Sciences, Linyi University, Linyi, China \\ 2 Institute of Entomology, College of Life Sciences, Nankai University, Tianjin, China \\ 3 Wenlai High School, Shanghai, China \\ ${ }^{4}$ College of Life Sciences, Chongqing Normal University, Chongqing, China \\ Corresponding Author: Xin Yu \\ Email address: lannysummer@163.com
}

Paracercion are common 'blue and black' colored damselflies. We explore the species boundaries of Paracercion (Odonata: Coenagrionidae) using ABGD, bPTP, GMYC and Distance-based clustering. We finally got the molecular data of all nine species of Paracercion . P. hieroglyphicum and $P$. melanotum were combined into one putative species based on cytochrome c oxidase I (COI ). However, they were separated into two putative species based on the nuclear segment including ITS1-5.8S-ITS2 (ITS). This suggests the introgression of mtDNA in Paracercion. Paracercion barbatum and Paracercion melanotum can be separated into two species based on COI, whereas they were combined into one putative species based on ITS, which suggests a hybridization event between them. The lower interspecific divergence (COI: $0.49 \%$ ) between $P$. barbatum and Paracercion v-nigrum indicates a recent speciation event in Paracercion. Paracercion sieboldii and $P$. $v$-nigrum can be separated into two putative species based on COI, while they were frequently merged into the same putative species based on ITS. This can be explained by incomplete lineage sorting in nDNA. Besides, $P$. pendulum and $P$. malayanum were synonymized as junior synonyms of $P$. melanotum. $P$. luzonicum was confirmed not to belong to Paracercion. The possibility of introgression, hybridization, recent speciation and incomplete lineage sorting makes species delimitation, based on molecular data, difficult and complicates understanding of the evolutionary history of Paracercion. The discordance in COI and ITS also indicates the value of using markers from different sources in species delimitation studies. 


\section{Integrative species delimitation based on COI, ITS,}

3 and morphological evidence illustrates a unique

4 evolutionary history of the genus Paracercion

\section{(Odonata: Coenagrionidae)}

Haiguang Zhang ${ }^{1}$, Xin Ning ${ }^{2,3}, \mathrm{Xin} \mathrm{Yu}^{4 *}$ and Wenjun $\mathrm{Bu}^{2}$

${ }^{1}$ College of Life Sciences, Linyi University, Linyi, 276000, China.

${ }^{2}$ Institute of Entomology, College of Life Sciences, Nankai University, Tianjin, 300071, China.

${ }^{3}$ Shanghai Wenlai High School, Shanghai, 201101, China.

Corresponding Author:

$\mathrm{X}$ in $\mathrm{Yu}$

College of Life Sciences, Chongqing Normal University, Chongqing 401331, China.

Email address: lannysummer@163.com.

\section{Abstract}

Paracercion are common 'blue and black' colored damselflies. We explore the species boundaries of Paracercion (Odonata: Coenagrionidae) using ABGD, bPTP, GMYC and Distance-based clustering. We finally got the molecular data of all nine species of Paracercion. $P$. hieroglyphicum and $P$. melanotum were combined into one putative species based on cytochrome c oxidase I (COI). However, they were separated into two putative species based on the nuclear segment including ITS1-5.8S-ITS2 (ITS). This suggests the introgression of mtDNA in Paracercion. Paracercion barbatum and Paracercion melanotum can be separated into two species based on COI, whereas they were combined into one putative species based on ITS, which suggests a hybridization event between them. The lower interspecific divergence (COI: $0.49 \%$ ) between P. barbatum and Paracercion v-nigrum indicates a recent speciation event in Paracercion. Paracercion sieboldii and P. v-nigrum can be separated into two putative species based on COI, while they were frequently merged into the same putative species based on ITS. This can be explained by incomplete lineage sorting in nDNA. Besides, $P$. pendulum and $P$. malayanum were synonymized as junior synonyms of $P$. melanotum. P. luzonicum was confirmed not to belong to Paracercion. The possibility of introgression, hybridization, recent speciation and incomplete lineage sorting makes species delimitation, based on molecular data, difficult and complicates understanding of the evolutionary history of Paracercion. The discordance in COI and ITS also indicates the value of using markers from different sources in species delimitation studies. 
40

41

42

43

44

45

46

47

48

49

50

51

52

53

54

55

56

57

58

59

60

61

62

63

64

65

66

67

68

69

70

71

72

73

74

75

76

77

78

\section{Introduction}

Correctly identifying species boundaries is important in taxonomic studies. Species delimitation based on molecular data plays an important role in integrative taxonomy (Satler et al., 2013; Andujar et al., 2014; Kergoat et al., 2015; Huang \& Knowles, 2016; Noguerales et al., 2018; Vidigal et al., 2018; Zhang et al., 2018; Masonick \& Weirauch, 2020; Zheng et al., 2020). A variety of species delimitation methods based on molecular data are used in taxonomic and systematic studies for testing species boundaries (Sites \& Marshall, 2003; Flot, 2015). The most widely used methods for species delimitation include ABGD (Puillandre et al., 2012), distancebased clustering (Meier et al., 2006; Brown et al., 2012), GMYC (Pons et al., 2006; Fujisawa \& Barraclough, 2013), and PTP (Zhang et al., 2013). Automatic Barcode Gap Discovery (ABGD) is an automatic procedure that sorts sequences into hypothetical species based on barcode gaps. Distance-based clustering uses pairwise distances for clustering sequences into "molecular operational taxonomic units" (MOTUs) (Floyd et al., 2002; Vogler \& Monaghan, 2007; Jones et al., 2011). The generalized Mixed Yule Coalescent (GMYC) method is a likelihood method for delimiting species by fitting within and between species branching models to an input tree. The Poisson Tree Processes (PTP) model assumes that the number of substitutions between species is significantly higher than the number of substitutions within species. bPTP is an updated version of PTP that adds Bayesian support values to delimited species on the input tree.

Although multilocus approaches are now common, single-gene methods still predominate in studies (Dellicour \& Flot, 2018). The COI (cytochrome c oxidase I) gene has been widely used in DNA-based species delimitation studies, especially after the introduction of DNA barcoding (Hebert et al., 2003; Blair \& Bryson, 2017). However, limitations of mtDNA, such as ancestral polymorphism, sex-biased gene flow and incomplete lineage sorting (Moritz \& Cicero, 2004; Rubinoff, 2006), complicate the definition of species boundaries based on mtDNA sequence data. Also, mtDNA introgression has been found in many insect groups (e.g. Bachtrog et al., 2006; Cong et al., 2017), fishes (Bernal et al., 2017), amphibians (Bryson Jr et al., 2014; Kuchta et al., 2018), reptiles (McGuire et al., 2007), birds (Dai et al., 2020) and mammals (Liu et al., 2011). The discordance between mitochondrial and nuclear genetic markers across taxa is now recognized and erroneous conclusions may occur in species delimitation studies based only on the mitochondrial gene (Papakostas et al., 2016). Therefore, multiple loci, including both mitochondrial and nuclear genes, which can provide independent evidence, are better suited for species delimitation. ITS is a nuclear genetic marker for DNA barcoding in botany and fungi, and it is very useful in systematic studies of the Odonata (Dow et al., 2015; Yu et al., 2015).

Weekers and Dumont (2004) established the genus Paracercion based on molecular data and morphological characters. Yu and Bu (2011) combined Coenagrion dorothea Fraser, 1924 as Paracercion dorothea (Fraser, 1924) and confirmed that Paracercion impar (Needham, 1930), one of the eight species described in Dumont (2004), was a junior synonym of $P$. dorothea. Ning 
et al. (2016) described a new species Paracercion ambiguum Kompier \& Yu, 2016 from Vietnam based on molecular and morphological characters. Twelve species are recorded in the genus Paracercion globally (Schorr \& Paulson, 2020). They are P. ambiguum Kompier \& Yu, 2016, P. barbatum (Needham, 1930), P. calamorum (Ris, 1916), P. dorothea (Fraser, 1924), $P$. hieroglyphicum (Brauer, 1865), P. luzonicum (Asahina, 1968), P. malayanum (Selys, 1876), $P$. melanotum (Selys, 1876), P. pendulum (Needham \& Gyger, 1939), P. plagiosum (Needham, 1929), P. sieboldii (Selys, 1876), and P. v-nigrum (Needham, 1930). Among these, three Southeast Asia species ( $P$. pendulum, P. luzonicum, and $P$. malayanum) are poorly studied. In the original descriptions, Selys put $P$. malayanum and $P$. melanotum into the same species group 3 , and mentioned that the only difference between them was "par les bandes dorsales noires des 1-4 segments decoupees en dessins etroits" in the former but not in the later (Selys-Longchamps, 1876). However, after studied hundreds of specimens of $P$. melanotum, the third author XY found both kinds of color patterns occurring in this species. Furthermore, we examined photos of a male specimen of $P$. malayanum in the RMNH (Natural History Museum, London, UK) collection (kindly provided by Dr. Rory A. Dow) and found it identical to male P. melanotum. The original description of $P$. pendulum noted that 'this species is nearest $C$. barbatum Needham (P. barbatum).....' (Needham \& Gyger, 1939). However, all the figures [cf. Figs. 239,242243,246 , in Needham \& Gyger (1939)] are virtually identical to P. melanotum, even the total blue colored face that is unique to this species. Therefore, we confirmed that both $P$. pendulum and $P$. malayanum are junior synonyms of $P$. melanotum. Furthermore, depending on the original description and figures, especially the shape of male caudal appendages ( $c f$. Figs. 51-52 in Asahina (1968)), P. luzonicum is definitely not a Paracercion species but belongs to Pseudoagrion or Coenagrion. In fact, this species is very similar to Pseudagrion australasiae. Finally, with the elimination of $P$. pendulum, $P$. malayanum, and $P$. luzonicum, nine nominal species of Paracercion were analyzed in this study.

Paracercion are common 'blue and black' colored damselflies distributed in East Asia. They are ubiquitous and common, even in large cities. Previous taxonomic studies were mainly based on morphological characteristics using a limited number of specimens. Paracercion species are often convergent in appearance while some of them exhibit large intraspecific variation. Therefore, species delimitation of Paracercion based on molecular data with adequate sample sizes was needed. We addressed the taxonomy of this genus by integrating both molecular and morphological data.

\section{Materials \& Methods}

\section{Taxon sampling}

The geographic distribution of Paracercion is shown in Figure 1. A total of 348 individuals of the genus Paracercion were collected from China, Japan, and Vietnam. For ITS, 16 sequences of Paracercion and seven sequences of out-groups downloaded from NCBI (National Centre for 
119 Biotechnology Information, https://www.ncbi.nlm.nih.gov/) were also included in the analyses.

120 In total, nine nominal species of Paracercion were analyzed with the molecular data. In addition,

121 the sequences of five genera: Coenagrion, Enallagma, Pseudagrion, Ischnura and Ceriagrion

122 were chosen as outgroups. The geographic coordinates of different locations were recorded using

123 a global positioning system (GPS) tool. For ease of DNA amplification, most of the specimens

124 were first deposited in anhydrous alcohol in the field and then stored in a freezer at $-20^{\circ} \mathrm{C}$ at the

125 College of Life Sciences, Chongqing Normal University. The detailed collecting information of

126 the 348 specimens is shown in Table S1.

127

128

DNA extraction, amplification and sequencing

129

130

One hind leg of each specimen was used to extract the genomic DNA by the Universal Genomic

131

132

133

134

135

136

137

138

139

140

141

142

143

144

145

146

147

148

149

150

151

152

153

154

155

156

157

158

DNA Kit (Beijing CoWin Biosciences) following manufacturer protocol. The mitochondrial gene cytochrome $\mathrm{c}$ oxidase subunit 1 (COI) and a nuclear segment including ITS1-5.8S-ITS2 (ITS) were first amplified following Yu et al. (2015). However, the amplification success rate of the ITS region was relatively low even using the clone method. All PCR products were visualized using $1 \%$ agarose gel electrophoresis and purified using a gel extraction kit (Sangon Biotech, Shanghai, China). The PCR products were sequenced by Beijing Genomics Institute or GENEWIZ based on Sanger's chain termination method.

Sequence analysis

The sequences files were viewed and edited in BioEdit 7.2.0 (Hall, 1999). Alignments of the COI sequences were translated into amino acids using MEGA X (Kumar et al., 2018) to detect the presence of pseudogenes. All of the sequences were saved as FASTA format and aligned with MAFFT version 7 (Katoh \& Standley, 2013).

\section{OTU delimitations}

The ABGD analysis was performed using the web version (http://wwwabi.snv.jussieu.fr/public/abgd/). The detailed arguments were as follows: Pmin = $0.001, \operatorname{Pmax}=0.1, \operatorname{setp}=10$, relative gap width $=1.5, \mathrm{Nb}$ bins (for distance distribution) $=20$ and the genetic distance model was set to Kimura (K80).

Distance-based clustering analysis was performed with the "tclust" function of the R package spider (Brown et al., 2012). Fixed empirical thresholds: 1\%, 2\%, 2.2\% and 3\% were selected following Zhang et al. (2017). The genetic distances required for clustering analysis were calculated with the "dist.dna" function of the ape package (Paradis et al., 2004) in R 3.6.3 (R Core Team 2020) using the K2P model (Kimura, 1980).

For GMYC analysis, the ultrametric trees were generated in Beast 2.5.2 (Bouckaert et al., 2019). Models of DNA sequence evolution were estimated by MrModeltest v2.3 (Nylander, 2004)

PeerJ reviewing PDF | (2020:11:55192:2:0:NEW 18 Apr 2021) 
159 based on Akaike Information Criterion (AIC). The nucleotide substitution model selected for 160 COI and ITS was GTR $+\mathrm{I}+\mathrm{G}$. We used the relaxed lognormal clock model and the coalescent 161 constant population tree prior. For each molecular marker, the length of Markov chain Monte 162 Carlo (MCMC) chains was set to 20,000,000 (ITS) and 50,000,000 (COI) with trees sampled 163 every 1000 generations. The convergence of each run was checked with Tracer v. 1.7 (Rambaut 164 et al., 2018). The first $10 \%$ of trees of each run were discarded, and the maximum clade 165 credibility tree (the posterior probability limit was set to 0.5 ) was reconstructed using the 166 TreeAnnotator (embed in BEAST package) with the mean node heights option. Afterward, the 167 maximum clade credibility tree was used as input for the GMYC analysis with the splits package 168 (Ezard et al., 2013) in R. The single-threshold method was used to generate the putative species. For bPTP analysis, the Maximum-likelihood trees were generated with IQ-TREE Version 1.6.10 (Nguyen et al., 2015). We obtained branch supports with the ultrafast bootstrap (Hoang et al., 2018) implemented in the IQ-TREE software. ModelFinder (Kalyaanamoorthy et al., 2017) was used to compute the log-likelihoods of an initial parsimony tree for different models and to select the best-fitting models of sequence evolution. The out-groups selected for rooting phylogenetic trees were removed in the bPTP analysis. The number of MCMC generations was set to 200,000; the thinning value was set to 100 and the burn in value was set to 0.1 . Other parameters were set to default values. The maximum likelihood solution result of bPTP is discussed in this study. The ultrametric tree and the combined results of different species delimitation methods were visualized by the R package ggtree (Yu et al., 2017).

179

180

\section{Network analysis}

181

The sequences files were transformed into haplotype sequences using the $\mathrm{R}$ package haplotypes (Aktas, 2020) with gaps and missing data included. Thereafter the haplotype network of each molecular marker was reconstructed with PopART 1.7 (Leigh \& Bryant, 2015) using the TCS method (Clement et al., 2000).

\section{Morphologic checking}

All of the living photos were taken in the field with a digital camera (Nikon D3200) (Bangkok, Thailand). Character photos were taken in the laboratory using the Zeiss V20 (Jena, Germany) microphotography system. Specimens were examined and dissected under a Zeiss V8 stereomicroscope. More than 600 specimens (including dried specimens) were identified by Xin $\mathrm{Yu}$ and Xin Ning in terms of the corresponding literatures (Dumont, 2004; Yu, 2008; Yu \& Bu, 2011; Ning et al., 2016). All the specimens were stored at the College of Life Sciences, Chongqing Normal University. The identification of the Paracercion species is not easy due to the prevalent convergent in appearance and intraspecific variations. The most important diagnostic morphologic characters are the shapes of male caudal appendages and genital ligulae and these were carefully examined. Generally, the variation of male genital ligulae among 
199

200

201

202

203

204

205

206

207

208

209

210

211

212

213

214

215

216

217

218

219

220

221

222

223

224

225

226

227

228

229

230

231

232

233

234

235

236

237

238

species is limited. This cannot provide more information on species delimitation other than to show some degree of relationship. The structure of the caudal appendages is the most credible diagnostic character. Based on this character, all the individuals can be divided into nine morphological defined species.

\section{Results}

\section{Molecular data}

We obtained molecular data from all the nine species of Paracercion. The COI dataset consisted of 348 sequences from Paracercion and 25 sequences from outgroups with a length of $1066 \mathrm{bp}$. There were 312 variable sites and 282 parsimony-informative sites in 348 COI sequences and most of the variation occurred in the third codon position. The ITS dataset consists of 66 sequences from Paracercion and seven sequences from out-groups. We obtained both COI and ITS sequences from all the nine species of Paracercion.

\section{Genetic distance (K2P distance)}

The COI genetic distances between $P$. hieroglyphicum and $P$. melanotum ranged from $0 \%$ $1.65 \%$. In comparison, the ITS genetic distances between $P$. hieroglyphicum and $P$. melanotum ranged from $9.58 \%$ to $10.89 \%$. Similarly, the COI genetic distances between $P$. barbatum and $P$. v-nigrum ranged from $0.19 \%$ to $1.16 \%$; the ITS genetic distances between P. barbatum and $P$. $v$ nigrum ranged from $3.03 \%$ to $8.44 \%$. The COI genetic distances of $P$. barbatum ranged from 0 to $0.19 \%$ (average value: $0.08 \%$, Table S2). The ITS genetic distances of $P$. barbatum ranged from 0 to $7.94 \%$ (average value: $3.01 \%$, Table S3). Regardless of the specimen, ChH03, the ITS genetic distances of $P$. barbatum ranged from 0 to $3.19 \%$. The COI genetic distances between $P$. barbatum and $P$. melanotum ranged from $9.46 \%$ to $10.58 \%$. The ITS genetic distances between $\mathrm{ChH03}$ and 11 specimens of $P$. melanotum ranged from $0.16 \%$ to $2.17 \%$; the ITS genetic distances between the other specimens of $P$. barbatum and the 11 specimens of $P$. melanotum ranged from $5.39 \%$ to $8.49 \%$. Although the COI genetic distances between $P$. sieboldii and $P$. $v$ nigrum ranged from $3.13 \%$ to $4.05 \%$, the ITS genetic distances between $P$. sieboldii and $P$. $v$ nigrum were relatively small $(0.17 \%-4.13 \%)$. The overlap between intraspecific and interspecific genetic distances indicated that the barcode gap does not exist in the COI and ITS markers (Fig. S1, Fig S2).

\section{ABGD analysis}

For COI $(\mathrm{P}=0.0129), 348$ specimens were divided into six groups. The specimens of $P$. barbatum, $P$. sieboldii and $P$. v-nigrum clustered into one group (Group 1). The specimens of $P$. hieroglyphicum and P. melanotum clustered into the same group (Group 4). The specimens of 
239 the other four morphologically defined species: P. ambiguum, P. calamorum, $P$. dorothea and $P$. 240 plagiosum were each divided into one of four different groups (Table S4).

241 For ITS $(\mathrm{P}=0.0129), 66$ specimens were divided into seven groups. The specimens of $P$.

242 barbatum (excluding ChH03), P. sieboldii and $P$. v-nigrum clustered into one group. One 243 specimen $(\mathrm{ChH} 03)$ of $P$. barbatum and the 11 specimens of $P$. melanotum were placed in the 244 same group. The specimens of the other five morphologically defined species: P. ambiguum, $P$. 245 calamorum, $P$. dorothea, $P$. hieroglyphicum and $P$. plagiosum were divided into five different 246 groups (Table S4).

247

248

Distance-based clustering analysis

249

250

If the threshold was set to $1 \%, 2 \%$ and $2.2 \%$, the number of MOTUs/clusters defined by

251

252 clustering analysis on COI was seven. In comparison, the number of MOTUs for ITS was 17, 11 and 10 separately (Fig. S3). For COI, if the threshold was set to 3\%, 348 specimens could be divided into seven MOTUs. The specimens of P. barbatum and P. v-nigrum were grouped into

254

255

256

257

258

259

260

261

262

263

264

265

266

267

268

269

270

271

272

273

274

275

276

277 the same MOTU; the specimens of $P$. hieroglyphicum and P. melanotum were also grouped into the same MOTU. The specimens of the other five morphologically defined species- $-P$. ambiguum, $P$. calamorum, $P$. dorothea, $P$. plagiosum and $P$. sieboldii-were divided into five different MOTUs (Table S5).

For ITS, if the threshold was set to 3\%, 66 specimens could be divided into seven MOTUs. The specimens of $P$. barbatum (excluding ChH03), P. sieboldii and P. v-nigrum were grouped into the same MOTU. One specimen $(\mathrm{ChH03})$ of $P$. barbatum and the 11 specimens of $P$. melanotum were divided into the same MOTU. The specimens of the other five morphologically defined species - P. ambiguum, $P$. calamorum, $P$. dorothea, $P$. hieroglyphicum and $P$. plagiosum-were divided into five different MOTUs (Table S5).

\section{GMYC analysis}

For COI, 145 haplotypes could be divided into seven putative species (Table 1). The 70 haplotypes of $P$. barbatum and $P$. v-nigrum were grouped into the same putative species; the 55 haplotypes of $P$. hieroglyphicum and $P$. melanotum were also grouped into the same putative species. The haplotypes of the other five morphologically defined species: $P$. ambiguum, $P$. calamorum, $P$. dorothea, $P$. plagiosum and $P$. sieboldii were divided into five different putative species (Table S6).

For ITS, 50 haplotypes could be divided into 12 putative species (Table 1). One haplotype (Hap_4, ChH03) of $P$. barbatum and the nine haplotypes of $P$. melanotum were included within the same putative species. Six haplotypes of $P$. barbatum were separated into three putative species. Five haplotypes of $P$. calamorum were separated into two putative species. Sixteen haplotypes of $P$. sieboldii and $P$. v-nigrum were separated into two putative species. The 
278 haplotypes of the other four morphologically defined species: P. ambiguum, $P$. dorothea, $P$. 279 hieroglyphicum and $P$. plagiosum were divided into four different putative species (Table S6).

280

281

282

283

284

285

286

287

288

289

290

291

292

293

294

295

296

297

298

299

300

301

302

303

304

305

306

307

308

309

310

311

312

313

314

315

316

317

bPTP analysis

A total of 145 COI haplotypes could be divided into seven tentative species using bPTP analysis. All the haplotypes of $P$. barbatum and $P$. v-nigrum were grouped into the same tentative species; all the haplotypes of $P$. hieroglyphicum and $P$. melanotum were also grouped into the same tentative species. The haplotypes of the other five morphologically defined species- $P$. ambiguum, $P$. calamorum, $P$. dorothea, $P$. plagiosum and $P$. sieboldii-were divided into five different tentative species (Table S7). The result of bPTP analysis on COI was consistent with the GMYC analysis.

A total of 50 ITS haplotypes could be divided into 10 tentative species by bPTP analysis. One haplotype (Hap_4, ChH03) of $P$. barbatum and the nine haplotypes of $P$. melanotum clustered into the same tentative species. Six haplotypes of $P$. barbatum were separated into three tentative species. Sixteen haplotypes of $P$. sieboldii and $P$. v-nigrum were merged into the same tentative species. The haplotypes of the other five morphologically defined species- $-P$. ambiguum, $P$ calamorum, $P$. dorothea, $P$. hieroglyphicum and $P$. plagiosum - were divided into five different tentative species (Table $\mathrm{S} 7$ ).

The combined results of species delimitation of different methods based on COI and ITS are shown in Figure 2 and Figure 3, respectively.

Network analysis

The COI haplotype network showed that the haplotypes of P. barbatum and P. v-nigrum were merged into one large group; however, they did not share any haplotypes. In comparison, the haplotypes of $P$. sieboldii were placed into a single group (Fig. 4A). All the haplotypes of $P$. hieroglyphicum and $P$. melanotum were also grouped into one large group. Two individuals of $P$. hieroglyphicum and two individuals of $P$. melanotum shared the same haplotype (Fig. 4B). The ITS haplotype network showed that the haplotypes of P. sieboldii and P. v-nigrum were merged into one nested group; the haplotypes of $P$. barbatum were separated into a single group (Fig. 5A). In addition, one haplotype of $P$. barbatum and the nine haplotypes of $P$. melanotum were merged into one group (Fig. 5B).

\section{Discussion}

Introgression in Paracercion

For COI, four methods including ABGD, Clustering, GMYC and bPTP all indicated that $P$. hieroglyphicum and P. melanotum belong to one putative species. For ITS, the results of all four methods support the conclusion that these two species are distinct. In addition, there are

PeerJ reviewing PDF | (2020:11:55192:2:0:NEW 18 Apr 2021) 
318 significant differences between $P$. hieroglyphicum and $P$. melanotum based on morphological 319 characters (Fig. 6), especially the male caudal appendages (Fig. 7). These differences support the

320

321

322

323

324

325

326

327

328

329

330

331

332

333

334

335

336

337

338

339

340

341

342

343

344

345

346

347

348

349

350

351

352

353

354

355

356

357

conclusion that these are two separate species. P. hieroglyphicum and P. melanotum are sympatric species in many areas (Fig. 1) and share similar shaped genital ligulae (Fig. 8). They have identical COI haplotypes (Fig. 4B). The morphological and molecular evidence argue for the introgression of mtDNA in P. hieroglyphicum and P. melanotum. Our field observations indicate that these two species have evolved reproductive isolation mechanisms. Males sometimes attempt to mate with nonconspecific females, but the latter are not receptive. In general, introgression in Paracercion was found in COI rather than ITS, which indicates that mtDNA may be more likely to show introgression than nDNA (Ballard \& Whitlock, 2004).

\section{Hybridization between P. barbatum and P. melanotum}

For ITS, four methods of species delimitation indicated that at least one specimen $(\mathrm{ChH} 03)$ of $P$. barbatum together with all specimens of $P$. melanotum should be the same tentative species. This indicates that $P$. barbatum and $P$. melanotum likely hybridize at Changhu, Yunnan. Several possible hybrid individuals from Changhu were found based on morphological characters (Fig. 9). P. barbatum is restricted to Northeast Yunnan while P. melanotum is widely distributed (Fig. 1), covering the range of $P$. barbatum. It should be extended further south since the two previous southeast species $P$. malayanum and $P$. pendulum were confirmed to be the same species.

Among them, the caudal appendage of a male specimen of $P$. malayanum in the RMNH (Natural History Museum, London, UK) collection (kindly provided by Dr. Rory A. Dow) (Fig. 7, O) is identical to male $P$. melanotum. Shapes of the male caudal appendages and genital ligula of $P$. barbatum are similar to that in P. melanotum (Fig. 9) and that may be why Needham and Gyger confused them. This also suggests the possibility of hybridization. It is worth noting that recent hybridization events can be detected by ITS rather than COI.

Species group of 'v-nigrum'

Results from both COI and ITS supported a very closely related species group including $P$. barbatum, $P$. sieboldii and $P$. v-nigrum. For COI, four methods-ABGD, clustering, GMYC and bPTP - all indicated that $P$. barbatum and $P$. v-nigrum are a single putative species. The low mean interspecific divergence between $P$. barbatum and $P$. v-nigrum (COI: $0.49 \%$ ) indicates a recent speciation event in Paracercion. For ITS, the results of GMYC and bPTP support that this pair of species were separated into two or more putative species. Furthermore, $P$. barbatum seems to be closely related to $P$. melanotum due to the hybridization discussed above. All the specimens of $P$. sieboldii and $P$. v-nigrum can be separated into two putative species in the four different methods based on COI. However, they were merged into the same putative species in ABGD, Clustering and bPTP analyses based on ITS. This discordance of species delimitation may be the result of incomplete lineage sorting in the nuclear DNA. 
358

359

360

361

362

363

364

365

366

367

368

369

370

371

372

373

374

375

376

377

378

379

380

381

382

383

384

385

386

387

388

389

390

391

392

393

394

395

396

397

P. barbatum, P. sieboldii and P. v-nigrum are allopatric. However, their distributions are obviously contiguous, namely, $P$. $v$-nigrum has the widest distribution range while $P$. barbatum is restricted to the southwest corner (northwest Yunnan) and $P$. sieboldii is isolated at the northeast portion (Japan) of this area (Fig. 1). P. barbatum, P. sieboldii and P. v-nigrum share similar morphological characters especially the shape of genital ligulae (Fig. 6). Therefore, these three species may have originated from one widely distributed ancestral species. Dumont (2004) and Ning et al. (2016) also suggested that $P$. sieboldii shared a common ancestor with the continental P. v-nigrum.

\section{Species delimitation methods}

All methods of species delimitation will sometimes fail to delimit species boundaries properly or will give conflicting results. The use of qualitative judgment will then be necessary (Sites \& Marshall, 2004). For species delimitation studies, multiple methods based on different principles and multiple loci underlying different evolutionary history should be included. Theoretically, the most realistic strategy is to accept delimitations that are congruent across methods and may represent actual evolutionary lineages. However, morphological characters are also important in species delimitation studies. Inferences drawn from species delimitation studies should be conservative (Carstens et al., 2013). For ITS, the number of putative species generated from bPTP and GMYC exceeded the total number of species determined from morphological characteristics. This was mainly due to the high rates of false positives of PTP and GMYC methods (Luo et al., 2018).

\section{Conclusions}

Six or Seven tentative species were indicated based on COI with four different methods, while seven, ten, or twelve tentative species were indicated based on ITS. Herein, neither COI nor ITS supported the nine species based on the morphological evidence. In Paracercion, species delimitation results based on ITS were relatively more reliable than those based on COI. $P$. pendulum and $P$. malayanum were synonymized as junior synonyms of $P$. melanotum. $P$. luzonicum was confirmed not to belong to Paracercion. Combing both the morphological and molecular evidence, we insist on the genus Paracercion includes nine confirmed species. The possibility of introgression in COI causes difficulties for species delimitation based on molecular data. This phenomenon, together with the discovery of the possible hybridization and incomplete lineage sorting illustrates the unique evolutionary history of the genus Paracercion. Anyway, to confirm the existence of above introgression, hybridization, recent speciation, and incomplete lineage sorting, further analysis may need to conduct in the future. The discordance of the delimitations based on the COI and ITS markers demonstrates the importance of using both mitochondrial and nuclear genes in species delimitations studies. 
398

399

400

401

402

403

404

405

406

407

408

409

410

411

412

413

414

415

416

417

418

419

420

421

422

423

424

425

426

427

428

429

430

431

432

433

434

435

436

437

However, species delimitation based on one or two DNA markers may be questionable. Therefore, if possible, more genes should be used in species delimitation studies. Morphological characters and molecular data are complementary. If the results based on morphological characters and molecular data can match each other, the conclusions will be more reliable. Meanwhile, molecular taxonomy may also lead to a false conclusion without support from morphological characters.

\section{Acknowledgements}

We are grateful to Prof. Fumio Hayashi and Mr. Hong-guang Jin for providing important specimens. We also thank to Dr. Rory A. Dow for helping us with valuable literatures and photo of Southeast Asia species. This project was supported by the Chongqing Basic Research and Frontier Exploration Special Project (No. cstc2018jcyjAX0415) and the grant of Ministry of Science and Technology of China (No. 2015FY210300).

\section{References}

Aktas C. 2020. haplotypes: Manipulating DNA Sequences and Estimating Unambiguous Haplotype Network with Statistical Parsimony. R package version 1.1.2. https://CRAN.Rproject.org/package=haplotypes.

Andujar C, Arribas P, Ruiz C, Serrano J, and Gomez-Zurita J. 2014. Integration of conflict into integrative taxonomy: fitting hybridization in species delimitation of Mesocarabus (Coleoptera: Carabidae). Molecular Ecology 23:4344-4361. 10.1111/Mec.12793

Asahina S. 1968. Records and Notes on Philippine Odonata. Japanese Journal of Zoology 15:349-376.

Bachtrog D, Thornton K, Clark A, and Andolfatto P. 2006. Extensive introgression of mitochondrial DNA relative to nuclear genes in the Drosophila yakuba species group. Evolution 60:292-302. 10.1111/j.0014-3820.2006.tb01107.x

Ballard JW, and Whitlock MC. 2004. The incomplete natural history of mitochondria. Molecular Ecology 13:729-744. 10.1046/j.1365-294x.2003.02063.x

Bernal MA, Gaither MR, Simison WB, and Rocha LA. 2017. Introgression and selection shaped the evolutionary history of sympatric sister-species of coral reef fishes (genus: Haemulon). Molecular Ecology 26:639-652. 10.1111/mec.13937

Blair C, and Bryson RW, Jr. 2017. Cryptic diversity and discordance in single-locus species delimitation methods within horned lizards (Phrynosomatidae: Phrynosoma). Molecular Ecology Resources 17:1168-1182. 10.1111/1755-0998.12658

Bouckaert R, Vaughan TG, Barido-Sottani J, Duchene S, Fourment M, Gavryushkina A, Heled J, Jones G, Kuhnert D, De Maio N, Matschiner M, Mendes FK, Muller NF, Ogilvie HA, du Plessis L, Popinga A, Rambaut A, Rasmussen D, Siveroni I, Suchard MA, Wu CH, Xie D, 
438

439

440

441

442

443

444

445

446

447

448

449

450

451

452

453

454

455

456

457

458

459

460

461

462

463

464

465

466

467

468

469

470

471

472

473

474

475

476

477

Zhang C, Stadler T, and Drummond AJ. 2019. BEAST 2.5: An advanced software platform for Bayesian evolutionary analysis. PLoS Computational Biology 15:e1006650. 10.1371/journal.pcbi.1006650

Brown SDJ, Collins RA, Boyer S, Lefort MC, Malumbres-Olarte J, Vink CJ, and Cruickshank RH. 2012. Spider: An R package for the analysis of species identity and evolution, with particular reference to DNA barcoding. Molecular Ecology Resources 12:562-565. 10.1111/j.1755-0998.2011.03108.x

Bryson Jr RW, Smith BT, Nieto-Montes de Oca A, García-Vázquez UO, and Riddle BR. 2014. The role of mitochondrial introgression in illuminating the evolutionary history of Nearctic treefrogs. Zoological Journal of the Linnean Society 172:103-116. 10.1111/zoj.12169

Carstens BC, Pelletier TA, Reid NM, and Satler JD. 2013. How to fail at species delimitation. Molecular Ecology 22:4369-4383. 10.1111/Mec.12413

Clement M, Posada D, and Crandall KA. 2000. TCS: a computer program to estimate gene genealogies. Molecular Ecology 9:1657-1659. 10.1046/j.1365-294x.2000.01020.x

Cong Q, Shen J, Borek D, Robbins RK, Opler PA, Otwinowski Z, and Grishin NV. 2017. When COI barcodes deceive: complete genomes reveal introgression in hairstreaks. Proceedings of the Royal Society B: Biological Sciences 284:20161735. 10.1098/rspb.2016.1735

Dai C, Dong F, and Yang X. 2020. Morphotypes or distinct species? A multilocus assessment of two East Asian scimitar babblers (Aves, Timaliidae). Zoologica Scripta 49:265-279. $10.1111 /$ zsc. 12411

Dellicour S, and Flot JF. 2018. The hitchhiker's guide to single-locus species delimitation. Molecular Ecology Resources 18:1234-1246. 10.1111/1755-0998.12908

Dow RA, Hämäläinen M, and Stokvis FR. 2015. Revision of the genus Devadatta Kirby, 1890 in Borneo based on molecular and morphological methods, with descriptions of four new species (Odonata: Zygoptera: Devadattidae). Zootaxa 4033:301-349. 10.11646/zootaxa.4033.3.1

Dumont HJ. 2004. Distinguishing between the East-Asiatic representatives of Paracercion Weekers \& Dumont (Zygoptera: Coenagrionidae). Odonatologica 33:361-370.

Ezard T, Fujisawa T, and Barraclough T. 2013. splits: SPecies' LImits by Threshold Statistics. $R$ package version 10-19/r48 https://R-ForgeR-projectorg/projects/splits/.

Flot JF. 2015. Species Delimitation's Coming of Age. Systematic Biology 64:897-899. $10.1093 /$ sysbio/syv071

Floyd R, Abebe E, Papert A, and Blaxter M. 2002. Molecular barcodes for soil nematode identification. Molecular Ecology 11:839-850. 10.1046/j.1365-294x.2002.01485.x

Fujisawa T, and Barraclough TG. 2013. Delimiting species using single-locus data and the Generalized Mixed Yule Coalescent approach: a revised method and evaluation on simulated data sets. Systematic Biology 62:707-724. 10.1093/sysbio/syt033

Hall TA. 1999. BioEdit: A user-friendly biological sequence alignment editor and analysis program for Windows 95/98/NT. Nucleic Acids Symposium Series 41:95-98. 10.14601/Phytopathol_Mediterr-14998u1.29 
478 Hebert PDN, Cywinska A, Ball SL, and deWaard JR. 2003. Biological identifications through

479

480

481

482

483

484

485

486

487

488

489

490

491

492

493

494

495

496

497

498

499

500

501

502

503

504

505

506

507

508

509

510

511

512

513

514

515

516

DNA barcodes. Proceedings of the Royal Society B: Biological Sciences 270:313-321.

$10.1098 / \mathrm{rspb} .2002 .2218$

Hoang DT, Chernomor O, von Haeseler A, Minh BQ, and Vinh LS. 2018. UFBoot2: Improving the Ultrafast Bootstrap Approximation. Molecular Biology And Evolution 35:518-522. 10.1093/molbev $/ \mathrm{msx} 281$

Huang JP, and Knowles LL. 2016. The Species versus Subspecies Conundrum: Quantitative Delimitation from Integrating Multiple Data Types within a Single Bayesian Approach in Hercules Beetles. Systematic Biology 65:685-699. 10.1093/sysbio/syv119

Jones M, Ghoorah A, and Blaxter M. 2011. jMOTU and Taxonerator: turning DNA barcode sequences into annotated operational taxonomic units. PLoS One 6:e19259. 10.1371/journal.pone.0019259

Kalyaanamoorthy S, Minh BQ, Wong TKF, von Haeseler A, and Jermiin LS. 2017. ModelFinder: fast model selection for accurate phylogenetic estimates. Nature Methods 14:587-589. 10.1038/nmeth.4285

Katoh K, and Standley DM. 2013. MAFFT multiple sequence alignment software version 7: improvements in performance and usability. Molecular Biology And Evolution 30:772-780. 10.1093/molbev/mst010

Kergoat GJ, Toussaint EFA, Capdevielle-Dulac C, Clamens AL, Ong'amo G, Conlong D, van Den Berg J, Cugala D, Pallangyo B, Mubenga O, Chipabika G, Ndemah R, Sezonlin M, Bani G, Molo R, Ali A, Calatayud PA, Kaiser L, Silvain JF, and Le Ru B. 2015. Integrative taxonomy reveals six new species related to the Mediterranean corn stalk borer Sesamia nonagrioides (Lefebvre) (Lepidoptera, Noctuidae, Sesamiina). Zoological Journal of the Linnean Society 175:244-270. 10.1111/zoj.12275

Kimura M. 1980. A simple method for estimating evolutionary rates of base substitutions through comparative studies of nucleotide sequences. Journal of molecular evolution 16:111-120.10.1007/bf01731581

Kuchta SR, Brown AD, and Highton R. 2018. Disintegrating over space and time: Paraphyly and species delimitation in the Wehrle's Salamander complex. Zoologica Scripta 47:285-299. $10.1111 /$ zsc. 12281

Kumar S, Stecher G, Li M, Knyaz C, and Tamura K. 2018. MEGA X: Molecular Evolutionary Genetics Analysis across Computing Platforms. Molecular Biology And Evolution 35:15471549. 10.1093/molbev/msy096

Leigh JW, and Bryant D. 2015. POPART: full-feature software for haplotype network construction. Methods in Ecology and Evolution 6:1110-1116. 10.1111/2041-210x.12410

Liu J, Yu L, Arnold ML, Wu CH, Wu SF, Lu X, and Zhang YP. 2011. Reticulate evolution: frequent introgressive hybridization among Chinese hares (genus lepus) revealed by analyses of multiple mitochondrial and nuclear DNA loci. BMC Evolutionary

Biology 11:223. 10.1186/1471-2148-11-223

Peer) reviewing PDF | (2020:11:55192:2:0:NEW 18 Apr 2021) 
517 Luo A, Ling C, Ho SYW, and Zhu CD. 2018. Comparison of Methods for Molecular Species 518 Delimitation Across a Range of Speciation Scenarios. Systematic Biology 67:830-846.

$519 \quad 10.1093 /$ sysbio/syy011

520

521

522

523

524

525

526

527

528

529

530

531

532

533

534

535

536

537

538

539

540

541

542

543

544

545

546

547

548

549

550

551

552

553

554

555

556

Masonick P, and Weirauch C. 2020. Integrative species delimitation in Nearctic ambush bugs (Heteroptera: Reduviidae: Phymatinae): insights from molecules, geometric morphometrics and ecological associations. Systematic Entomology 45:205-223. 10.1111/syen.12388

McGuire JA, Linkem CW, Koo MS, Hutchison DW, Lappin AK, Orange DI, Lemos-Espinal J, Riddle BR, and Jaeger JR. 2007. Mitochondrial introgression and incomplete lineage sorting through space and time: phylogenetics of crotaphytid lizards. Evolution 61:2879-2897. 10.1111/j.1558-5646.2007.00239.x

Meier R, Shiyang K, Vaidya G, and Ng PKL. 2006. DNA barcoding and taxonomy in diptera: a tale of high intraspecific variability and low identification success. Systematic

Biology 55:715-728. 10.1080/10635150600969864

Moritz C, and Cicero C. 2004. DNA barcoding: promise and pitfalls. PLoS Biology 2:e354. 10.1371/journal.pbio.0020354

Needham JG, and Gyger MK. 1939. The Odonata of the Philippines, II. Philippine Journal of Science 70:239-314.

Nguyen LT, Schmidt HA, von Haeseler A, and Minh BQ. 2015. IQ-TREE: a fast and effective stochastic algorithm for estimating maximum-likelihood phylogenies. Molecular Biology And Evolution 32:268-274. 10.1093/molbev/msu300

Ning X, Kompier T, Yu X, and Bu W. 2016. Paracercion ambiguum sp. nov. from Lang Son, Vietnam (Zygoptera: Coenagrionidae). Zootaxa 4144:263-275. 10.11646/zootaxa.4144.2.8

Noguerales V, Cordero PJ, and Ortego J. 2018. Integrating genomic and phenotypic data to evaluate alternative phylogenetic and species delimitation hypotheses in a recent evolutionary radiation of grasshoppers. Molecular Ecology 27:1229-1244.

$10.1111 / \mathrm{mec} .14504$

Nylander JAA. 2004. MrModeltest v2. Program distributed by the author. Evolutionary Biology Centre, Uppsala University.

Papakostas S, Michaloudi E, Proios K, Brehm M, Verhage L, Rota J, Pena C, Stamou G, Pritchard VL, Fontaneto D, and Declerck SA. 2016. Integrative Taxonomy Recognizes Evolutionary Units Despite Widespread Mitonuclear Discordance: Evidence from a Rotifer Cryptic Species Complex. Systematic Biology 65:508-524. 10.1093/sysbio/syw016

Paradis E, Claude J, and Strimmer K. 2004. APE: Analyses of Phylogenetics and Evolution in R language. Bioinformatics 20:289-290. 10.1093/bioinformatics/btg412

Pons J, Barraclough TG, Gomez-Zurita J, Cardoso A, Duran DP, Hazell S, Kamoun S, Sumlin WD, and Vogler AP. 2006. Sequence-based species delimitation for the DNA taxonomy of undescribed insects. Systematic Biology 55:595-609. 10.1080/10635150600852011

Puillandre N, Lambert A, Brouillet S, and Achaz G. 2012. ABGD, Automatic Barcode Gap Discovery for primary species delimitation. Molecular Ecology 21:1864-1877. 10.1111/j.1365-294X.2011.05239.x

Peer) reviewing PDF | (2020:11:55192:2:0:NEW 18 Apr 2021) 
557 R Core Team. 2020. R: A language and environment for statistical computing. R Foundation for

558

559

560

561

562

563

564

565

566

567

568

569

570

571

572

573

574

575

576

577

578

579

580

581

582

583

584

585

586

587

588

589

590

591

592

593

594

595

Statistical Computing, Vienna, Austria. URL https://www.R-project.org/.

Rambaut A, Drummond AJ, Xie D, Baele G, and Suchard MA. 2018. Posterior Summarization in Bayesian Phylogenetics Using Tracer 1.7. Systematic Biology 67:901-904. $10.1093 /$ sysbio/syy032

Rubinoff D. 2006. Utility of mitochondrial DNA barcodes in species conservation. Conservation Biology 20:1026-1033. 10.1111/j.1523-1739.2006.00372.x

Satler JD, Carstens BC, and Hedin M. 2013. Multilocus species delimitation in a complex of morphologically conserved trapdoor spiders (mygalomorphae, antrodiaetidae, aliatypus). Systematic Biology 62:805-823. 10.1093/sysbio/syt041

Schorr M, and Paulson D. 2020. List of Odonata of the world [Online];Available from: http://www.pugetsound.edu/academics/academic-resources/slatermuseum/biodiversity-resources/dragonflies/world-odonata-list2/ (accessed 12 March 2020).

Selys-Longchamps M E. 1876. Synopsis Des Agrionines, legion: Agrion (suite). Le Genre Agrion. Lu a l'Academie royale des sciences de Belgique, dans sa seance du 5 fevrier. 536539.

Sites JW, and Marshall JC. 2003. Delimiting species: a Renaissance issue in systematic biology. Trends in Ecology \& Evolution 18:462-470. 10.1016/s0169-5347(03)00184-8

Sites JW, and Marshall JC. 2004. Operational criteria for delimiting species. Annual Review of Ecology Evolution and Systematics 35:199-227. 10.1146/annurev.ecolsys.35.112202.130128

Vidigal THDA, Coscarelli D, Paixão H, Bernardes S, Montresor LC, and Pepato AR. 2018. Integrative taxonomy of the neotropical genus Omalonyx (Elasmognatha:

Succineidae). Zoologica Scripta 47:174-186. 10.1111/zsc.12271

Vogler AP, and Monaghan MT. 2007. Recent advances in DNA taxonomy. Journal of Zoological Systematics and Evolutionary Research 45:1-10. 10.1111/j.14390469.2006.00384.x

Weekers PHH, and Dumont HJ. 2004. A molecular study of the relationship between the coenagrionid genera Erythromma and Cercion, with the creation of Paracercion gen. nov for the East Asiatic "Cercion" (Zygoptera: Coenagrionidae). Odonatologica 33:181 - 188.

Yu G, Smith DK, Zhu H, Guan Y, and Lam TT-Y. 2017. ggtree: an r package for visualization and annotation of phylogenetic trees with their covariates and other associated data. Methods in Ecology and Evolution 8:28-36. 10.1111/2041-210x.12628

Yu X. 2008. A taxonomic study on the superfamilies Coenagrionoidea and Lestoidea (Odonata: Zygoptera) from China. Doctoral Dissertation, Nankai University, Tianjin.

$\mathrm{Yu} \mathrm{X}$, and Bu WJ. 2011. Chinese damselflies of the genus Coenagrion (Zygoptera:

Coenagrionidae). Zootaxa 2808:31 - 40. 10.11646/zootaxa.2808.1.3

Yu X, Xue J, Hämäläinen M, Liu Y, and Bu W. 2015. A revised classification of the genus Matrona Selys, 1853 using molecular and morphological methods (Odonata:

Calopterygidae). Zoological Journal of the Linnean Society 174:473-486. 10.1111/zoj.12253

Peer) reviewing PDF | (2020:11:55192:2:0:NEW 18 Apr 2021) 
596 Zhang F, Jantarit S, Nilsai A, Stevens MI, Ding Y, and Satasook C. 2018. Species delimitation in 597 the morphologically conserved Coecobrya (Collembola: Entomobryidae): A case study 598 integrating morphology and molecular traits to advance current taxonomy. Zoologica $599 \quad$ Scripta 47:342-356. 10.1111/zsc.12279

600 Zhang HG, Lv MH, Yi WB, Zhu WB, and Bu WJ. 2017. Species diversity can be overestimated 601 by a fixed empirical threshold: insights from DNA barcoding of the genus Cletus

602 (Hemiptera: Coreidae) and the meta-analysis of COI data from previous phylogeographical 603 studies. Molecular Ecology Resources 17:314-323. 10.1111/1755-0998.12571

604 Zhang J, Kapli P, Pavlidis P, and Stamatakis A. 2013. A general species delimitation method 605 with applications to phylogenetic placements. Bioinformatics 29:2869-2876.

$606 \quad$ 10.1093/bioinformatics/btt499

607 Zheng C, Ye Z, Zhu X, Zhang H, Dong X, Chen P, and Bu W. 2020. Integrative taxonomy 608 uncovers hidden species diversity in the rheophilic genus Potamometra (Hemiptera:

609 Gerridae). Zoologica Scripta 49:174-186. 10.1111/zsc.12401

610 
Figure 1

Distribution of the genus Paracercion.

Fig. 1 Distribution of the genus Paracercion. The morphospecies of Paracercion are represented by different shapes and colors. Distribution maps were generated using the software ArcGIS 10 (ESRI, Redlands, CA, USA). 


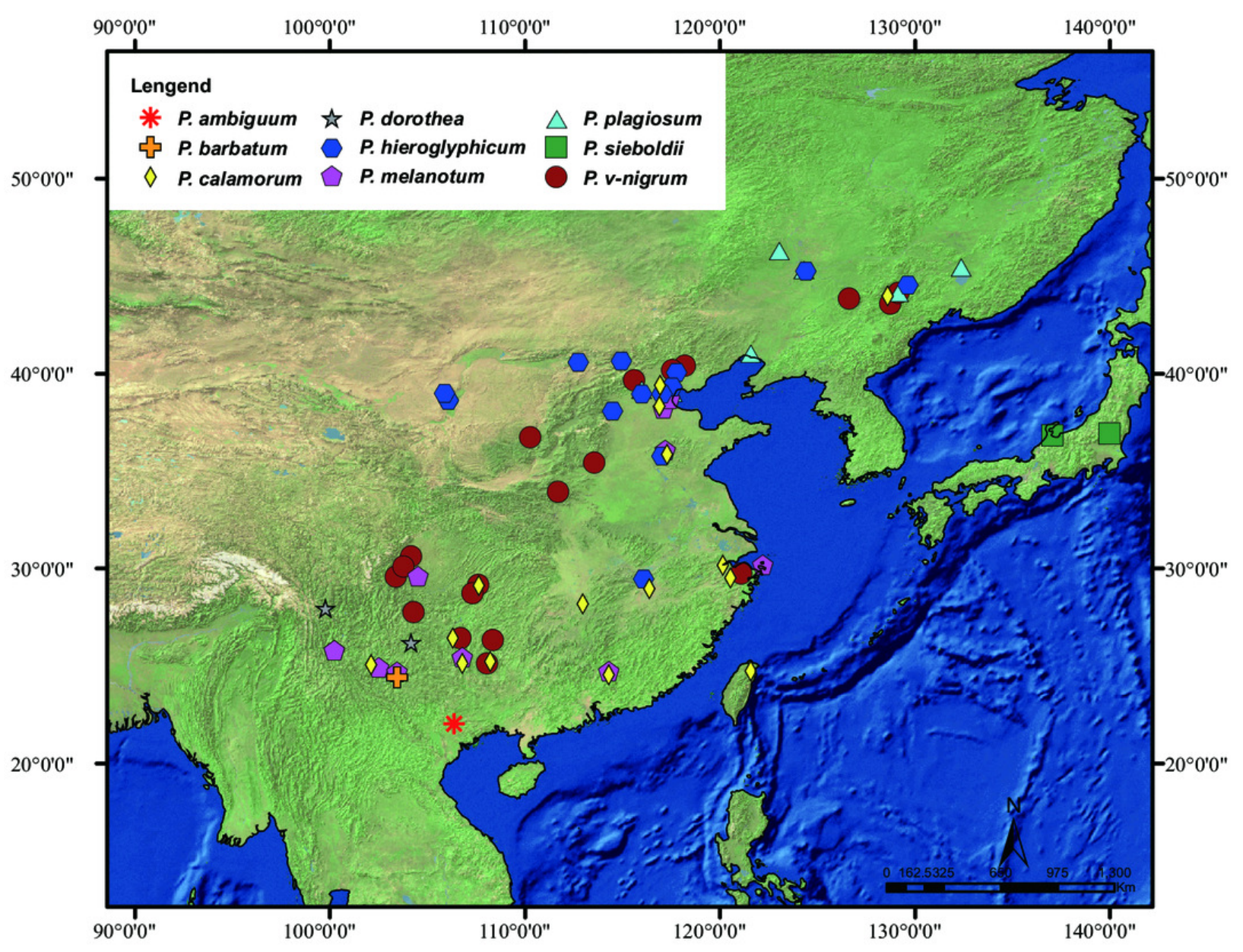




\section{Figure 2}

Comparison of species delimitation results of different methods of Paracercion based on the COI haplotypes.

Fig. 2 Comparison of species delimitation results of different methods of Paracercion based on the COI haplotypes. The maximum clade credibility tree generated from a BEAST analysis is colored by nine morphospecies of Paracercion.

Species

Paracercion ambiguum

Paracercion barbatum

Paracercion calamorum

Paracercion dorothea

Paracercion hieroglyphicum

Paracercion melanotum

Paracercion plagiosum

Paracercion sieboldii

Paracercion v-nigrum
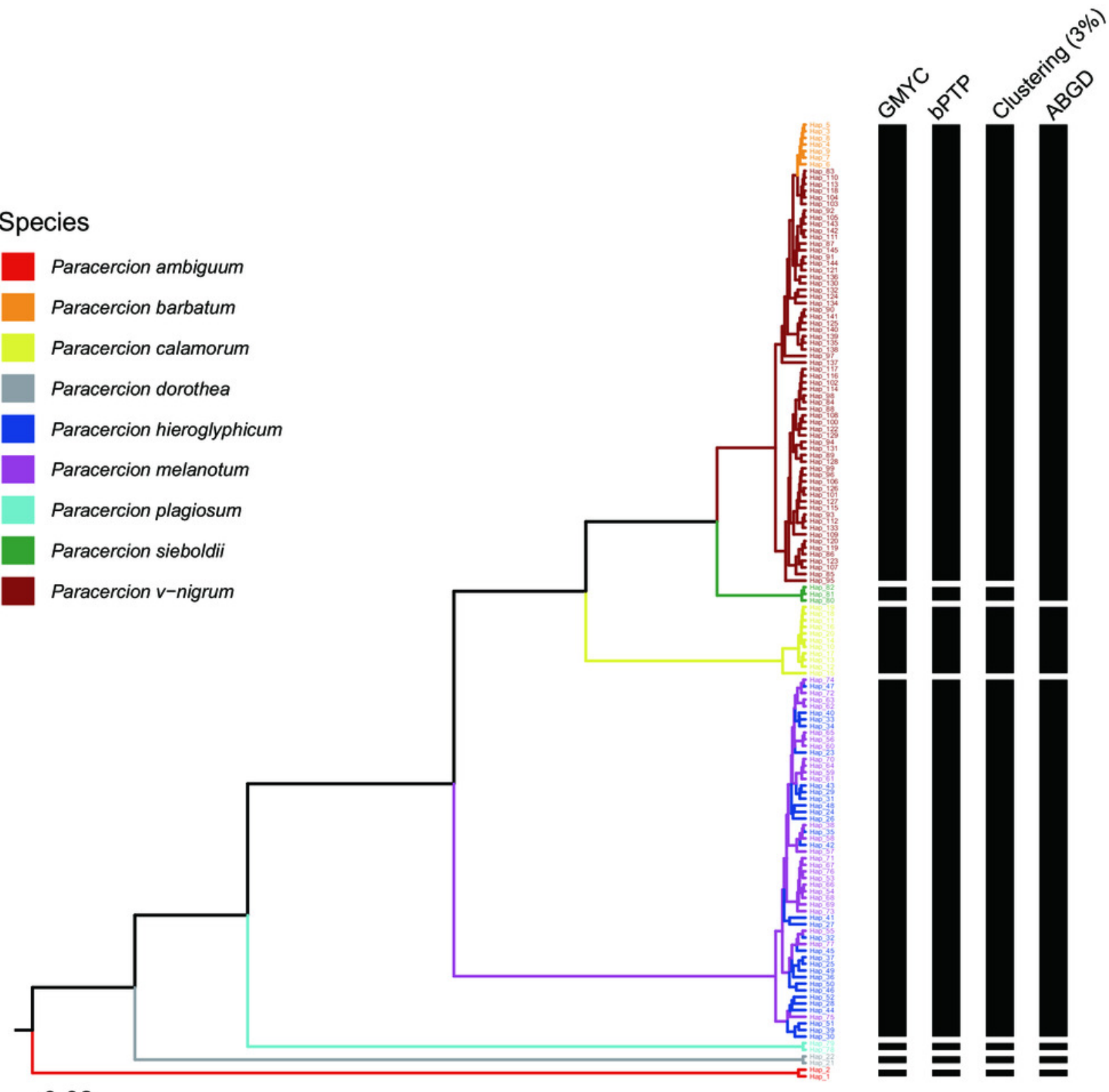

0.02 
Figure 3

Comparison of species delimitation results of Paracercion using different methods based on the ITS haplotypes.

Fig. 3 Comparison of species delimitation results of Paracercion using different methods based on the ITS haplotypes. The maximum clade credibility tree generated from a BEAST analysis is colored by nine morphospecies of Paracercion. The hybrid individual (ChH03, Hap_4) was indicated with the red arrow.

\section{Species}

Paracercion ambiguum

Paracercion barbatum

Paracercion calamorum

Paracercion dorothea

Paracercion hieroglyphicum

Paracercion melanotum

Paracercion plagiosum

Paracercion sieboldii

Paracercion v-nigrum

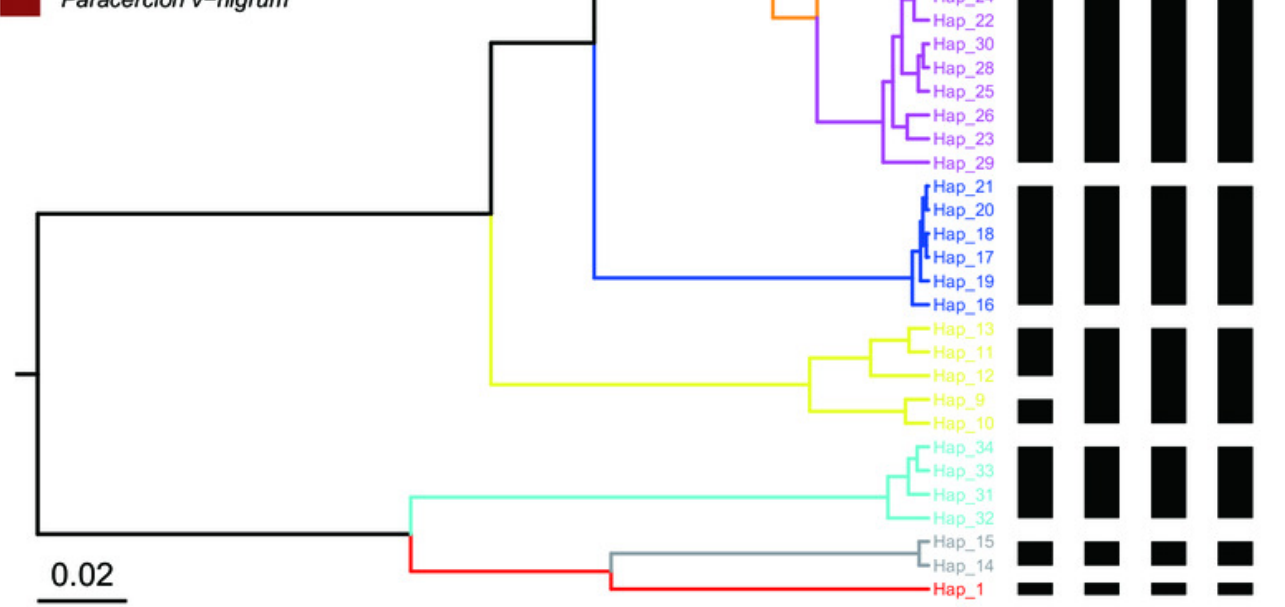


Figure 4

TCS haplotype networks of different species based on the COI gene.

Fig. 4 TCS haplotype networks of different species based on the COI gene. (A) P. barbatum , P. sieboldii and P. v-nigrum; (B) P. hieroglyphicum and P. melanotum. 
A

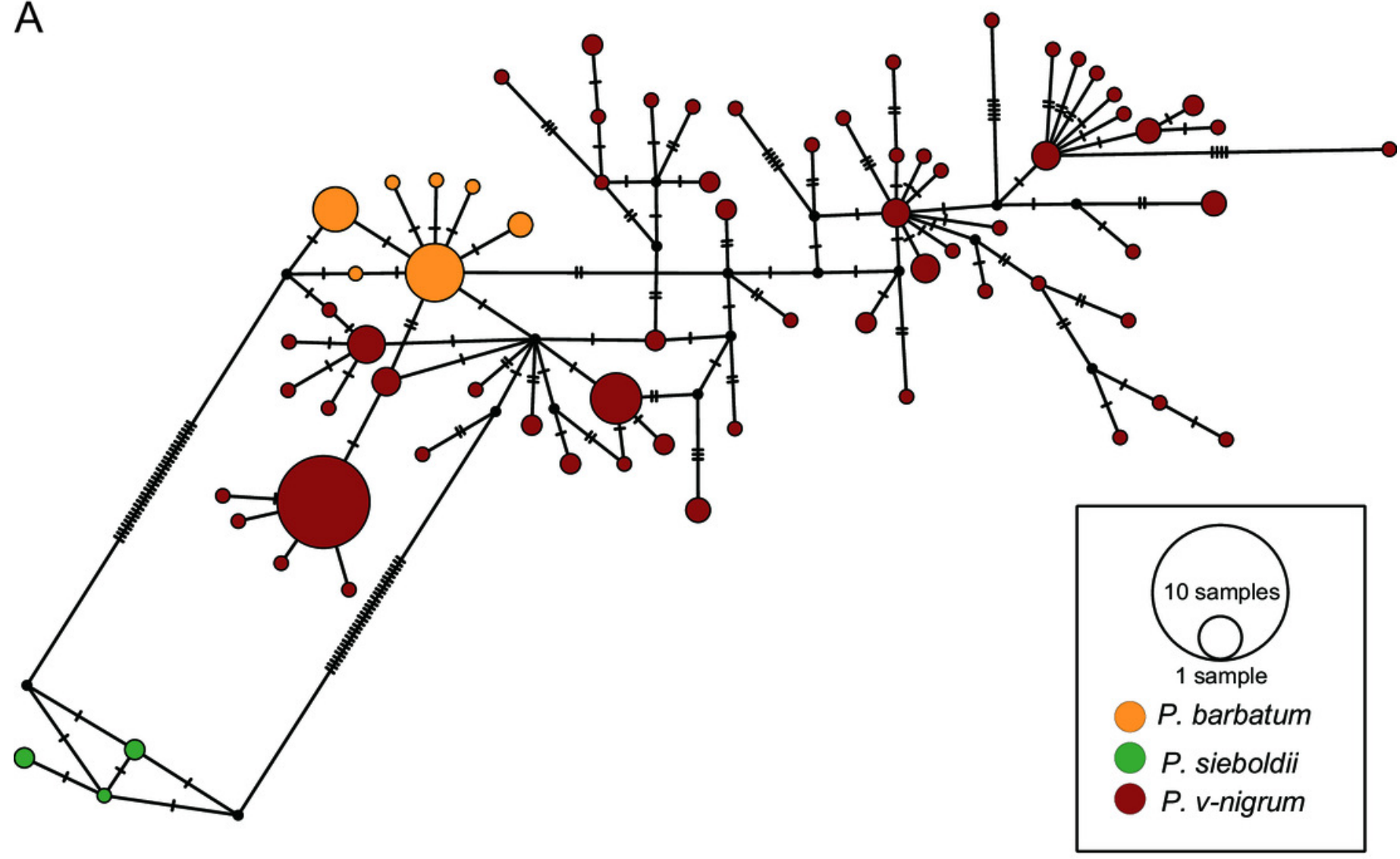

B
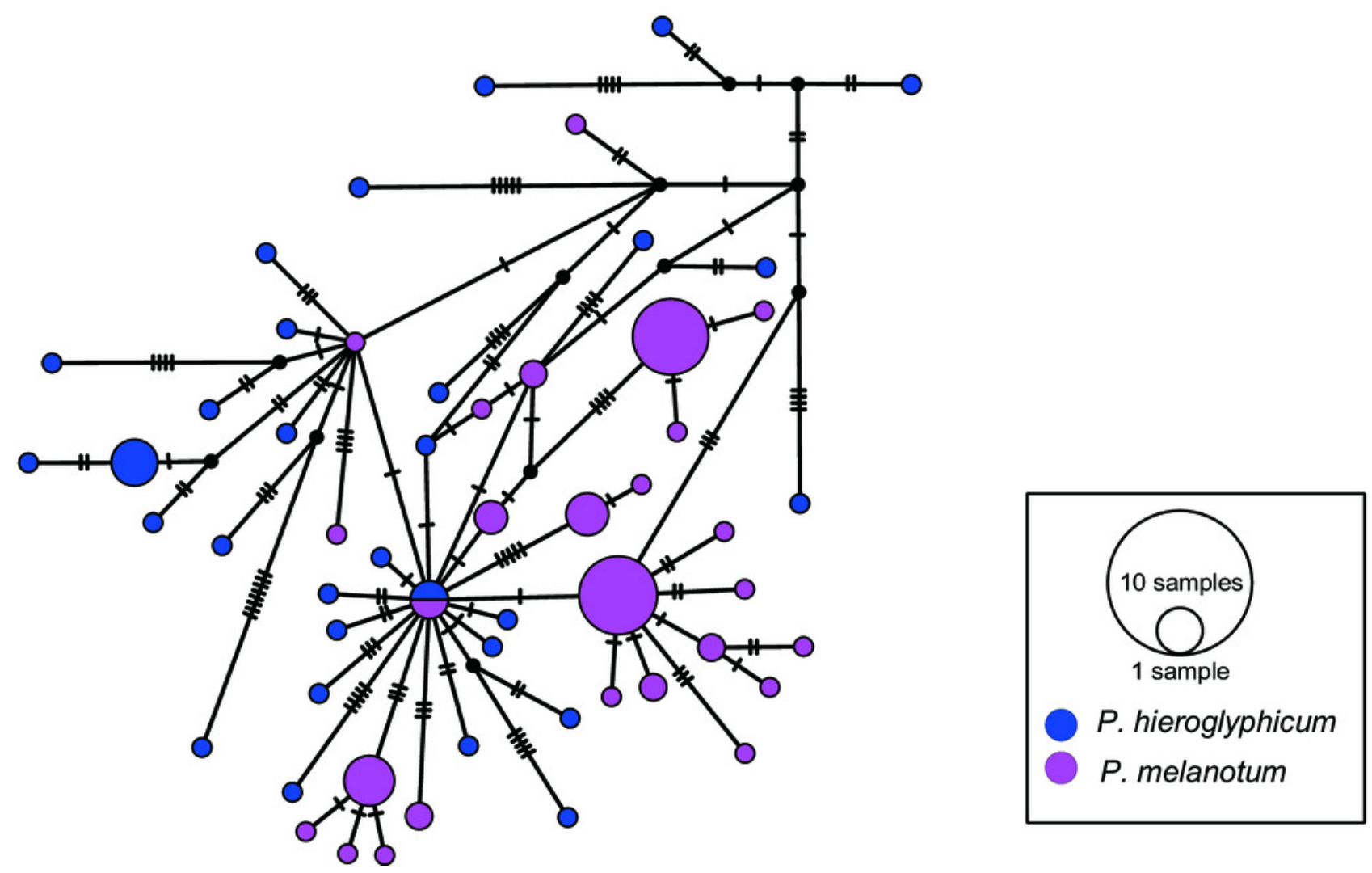
Figure 5

TCS haplotype networks of different species based on the ITS marker.

Fig. 5 TCS haplotype networks of different species based on the ITS marker. (A) P. barbatum, P. sieboldii and P. v-nigrum; (B) P. barbatum and P. melanotum. The hybrid individual (ChH03) was indicated with the red arrow. 


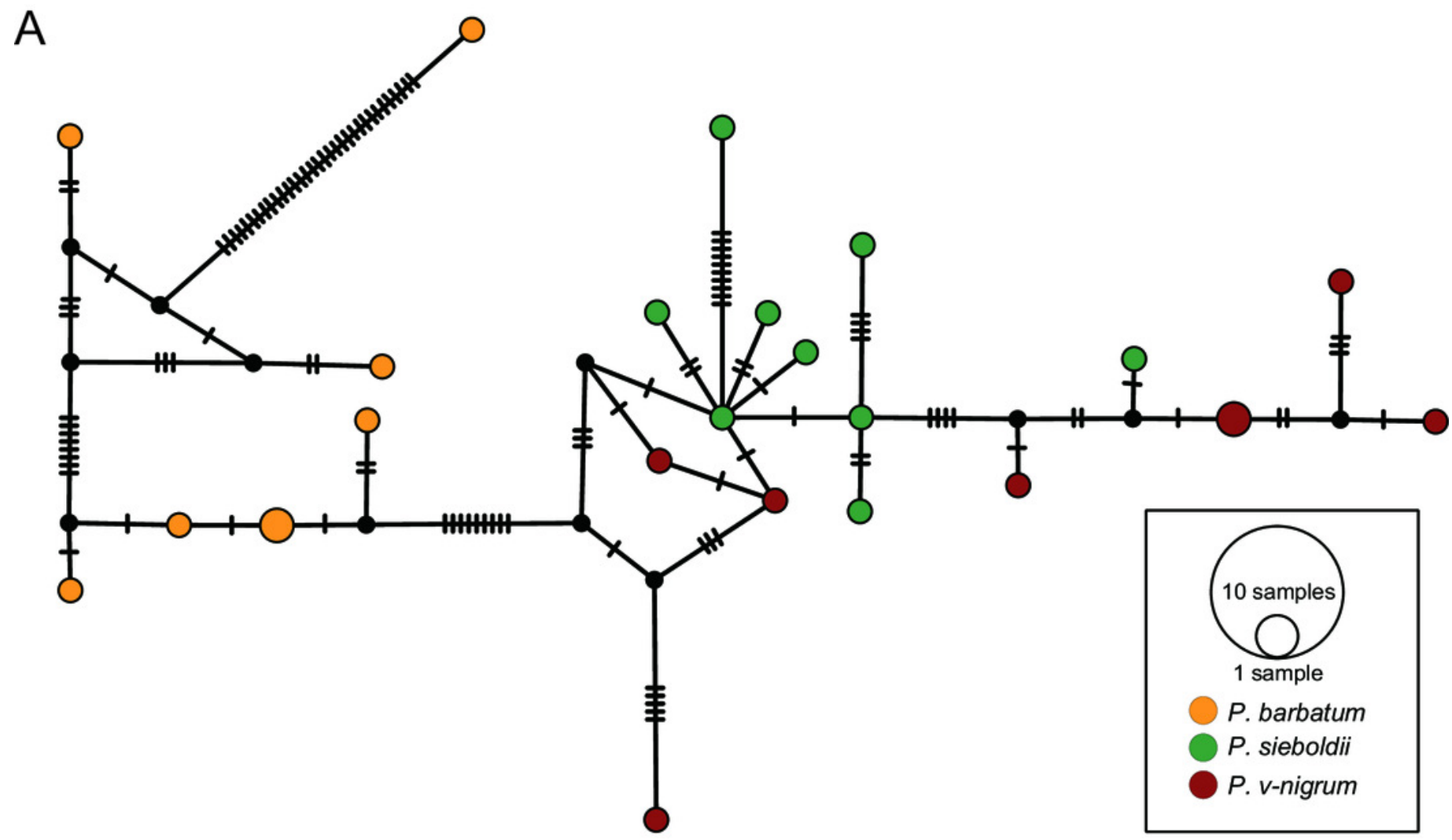

B

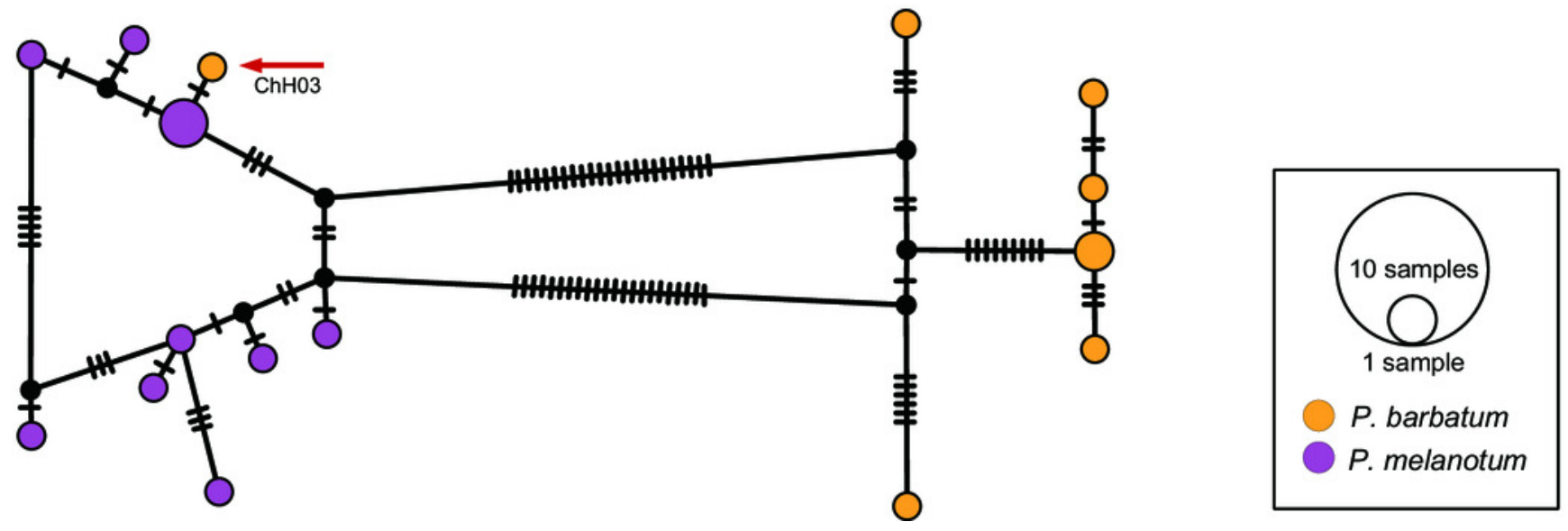




\section{Figure 6}

Habitus of Paracercion spp.

Fig. 6 Habitus of Paracercionspp. (A) P. ambiguum; (B) P. calamorum; (C) P. dorothea; (D) P. hieroglyphicum; (E-F) P. melanotum, show color pattern varitation; (G) P. plagiosum; (H-I) P. v-nigrum, show color pattern varitation; (J) P. barbatum.

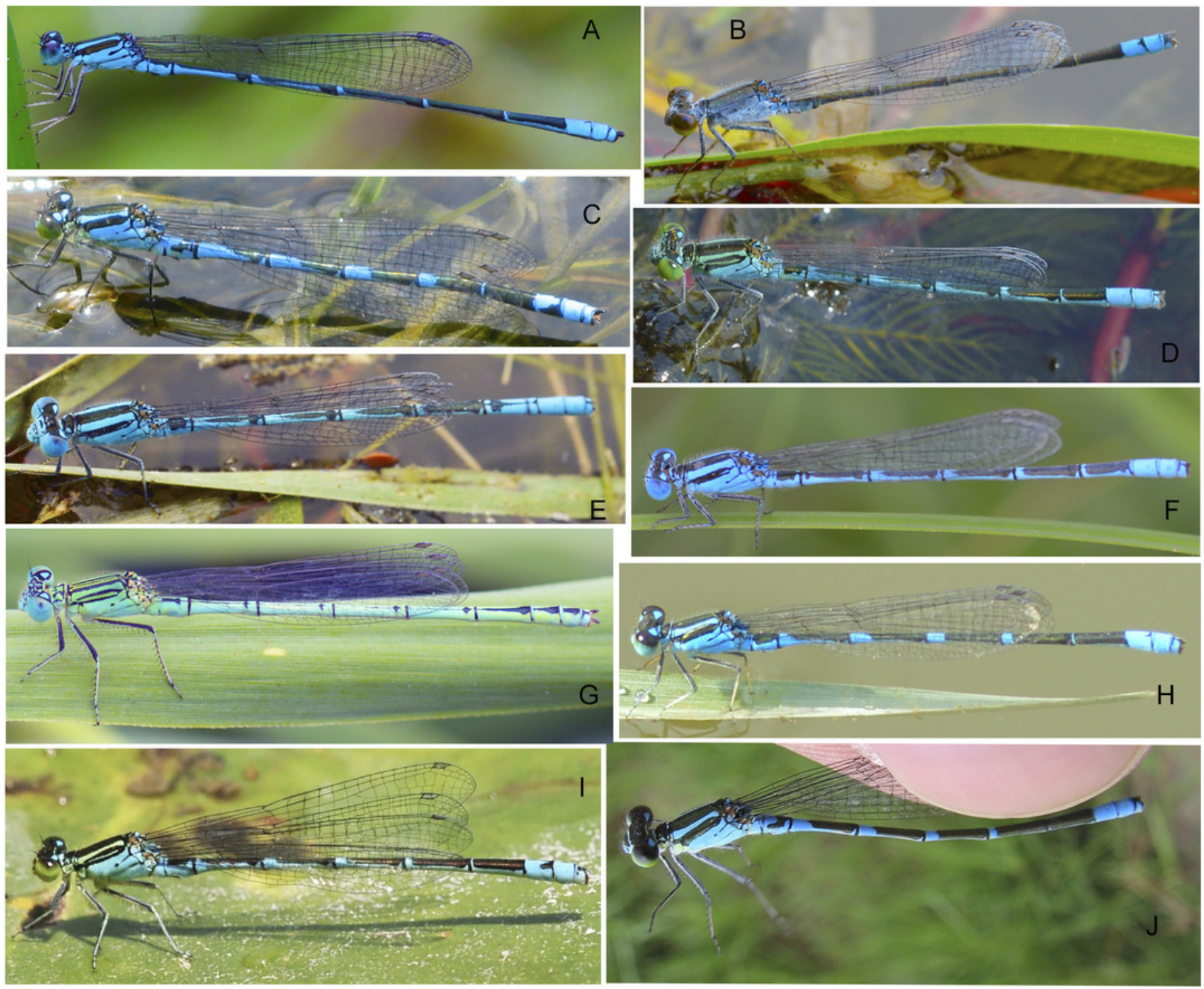




\section{Figure 7}

Male caudal appendages (rear view) of Paracercion spp. from different populations.

Fig. 7 Male caudal appendages (rear view) of Paracercion spp. from different populations. Male caudal appendages (rear view) of Paracercion spp. from different populations. (A-C) $P$. calamorum: (A) Shandong, (B) Heilongjiang, (C) Yunnan; (D-E) P. dorothea, Yunnan; (F-G) P. plagiosum: (F) Tianjin, (G) Heilongjiang; (H-J) P. hieroglyphicum: (H) Shandong, (I) Tianjin, (J) Ningxia; (K-N) P. melanotum: (K) Shandong, (I) Tianjin, (M-N) Yunnan; (O) P. malayanum specimen of RMNH (Photo credit: Rory A. Dow) ; (P-T) P. v-nigrum: (P) Beijing, (Q) Sichuan, (R) Heilongjiang, (S) Guizhou, (T) Guangxi; (U-V) P. barbatum, Yunnan; (W-X) P. sieboldii, Japan. 

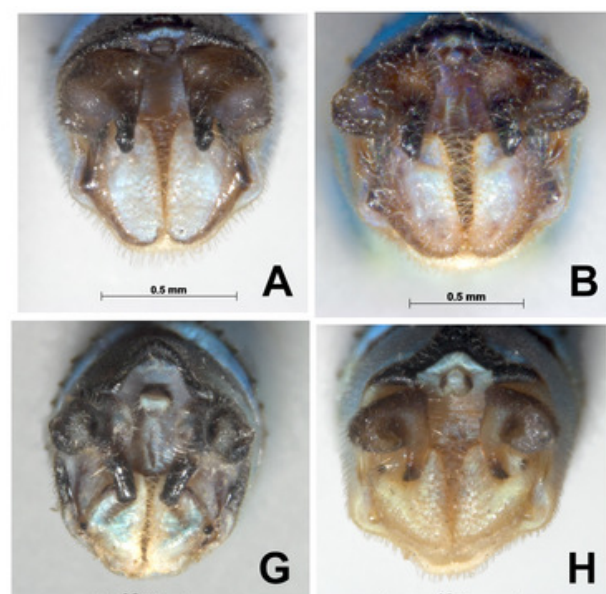

o.s mm
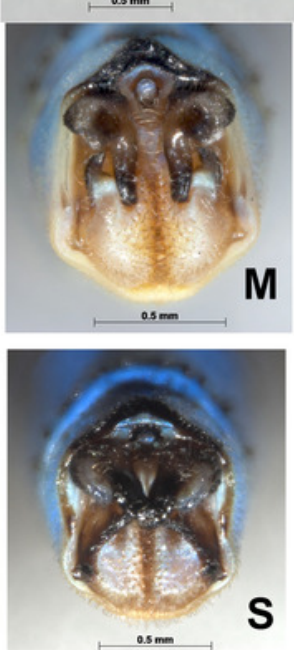

H
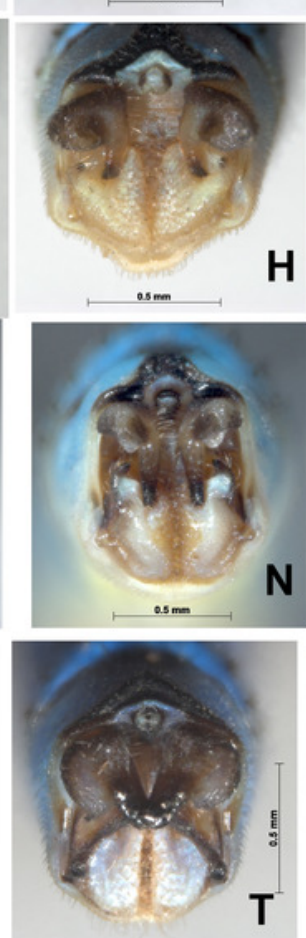
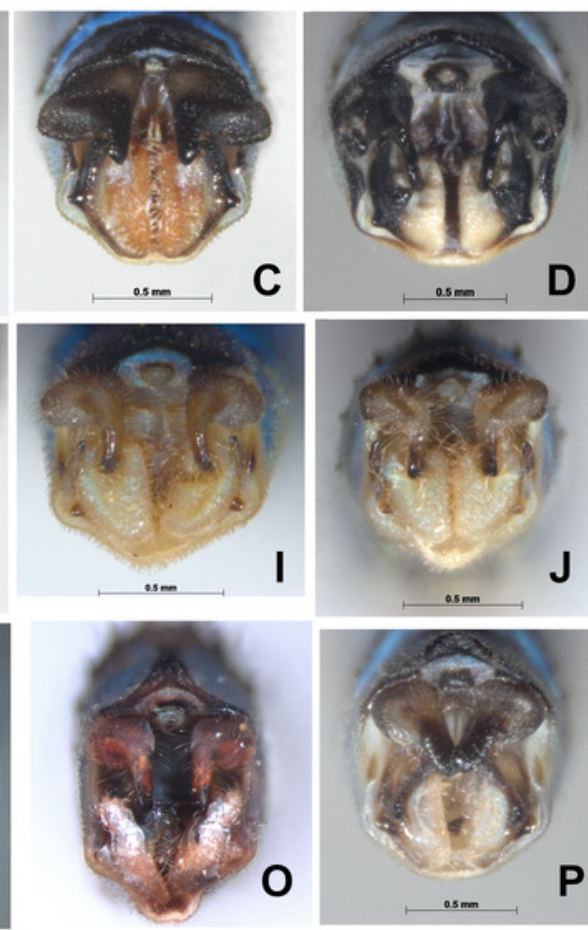

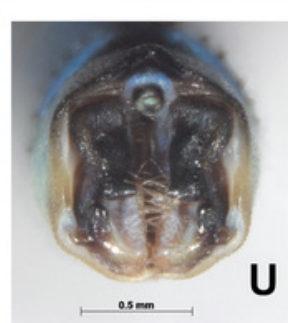

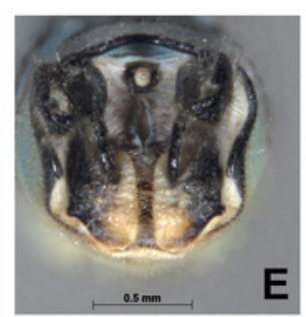
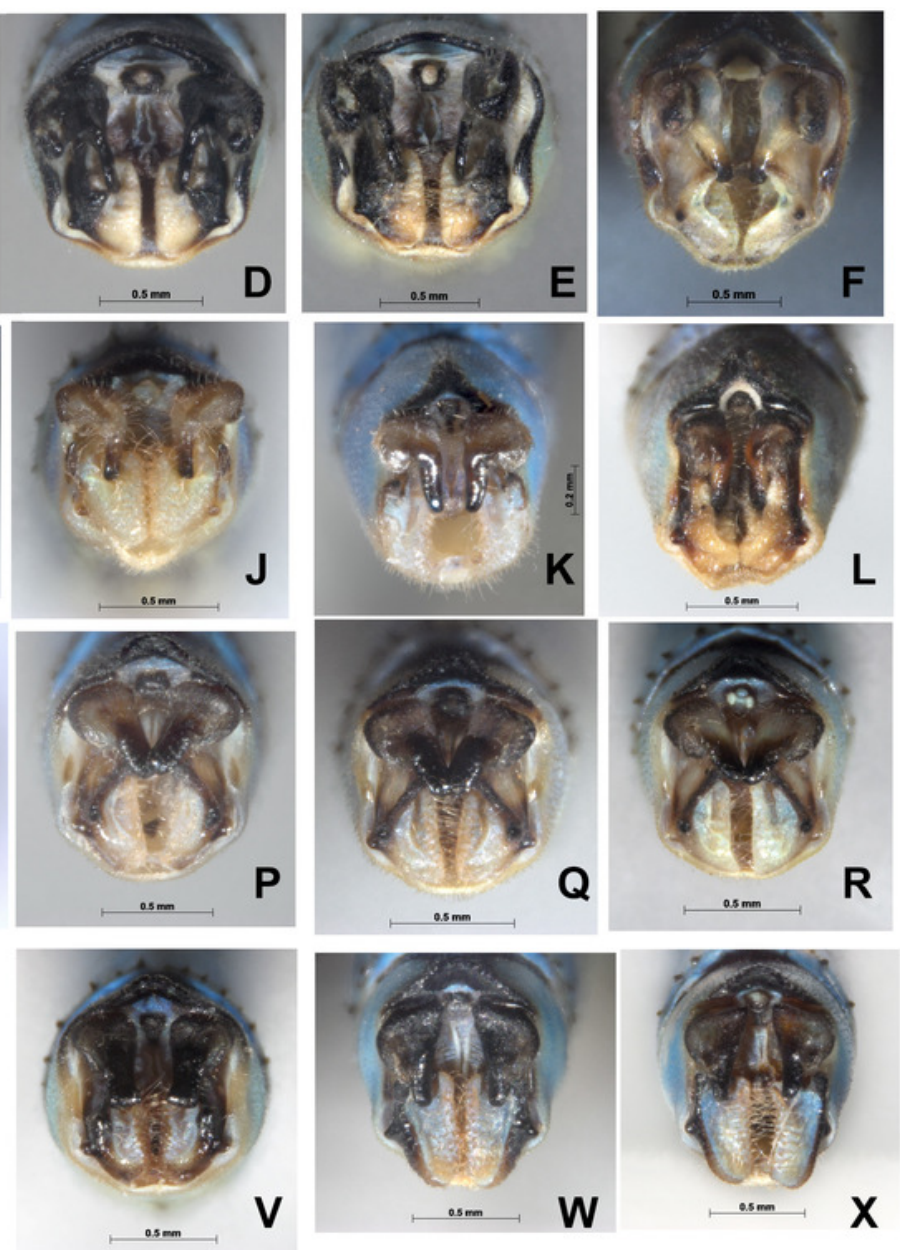


\section{Figure 8}

Male genital ligulae (ventral view) of Paracercion spp. from different populations.

Fig. 8 Male genital ligulae (ventral view) ofParacercion spp. from different populations. (A-C) P. calamorum: (A) Shandong, (B) Heilongjiang, (C) Yunnan; (D-E) P. dorothea, Yunnan; (F-G) P. plagiosum: (F) Tianjin, (G) Heilongjiang; (H-J) P. hieroglyphicum: (H) Shandong, (I) Tianjin, (J) Ningxia; (K-N) P. melanotum: (K) Shandong, (L) Tianjin, (M-N) Yunnan; (O) P. ambiguum, Vietnam; (P-T) P. v-nigrum: (P) Beijing, (Q) Sichuan, (R) Heilongjiang, (S) Guizhou, (T) Guangxi; (U-V) P. barbatum, Yunnan; (W-X) P. sieboldii, Japan.

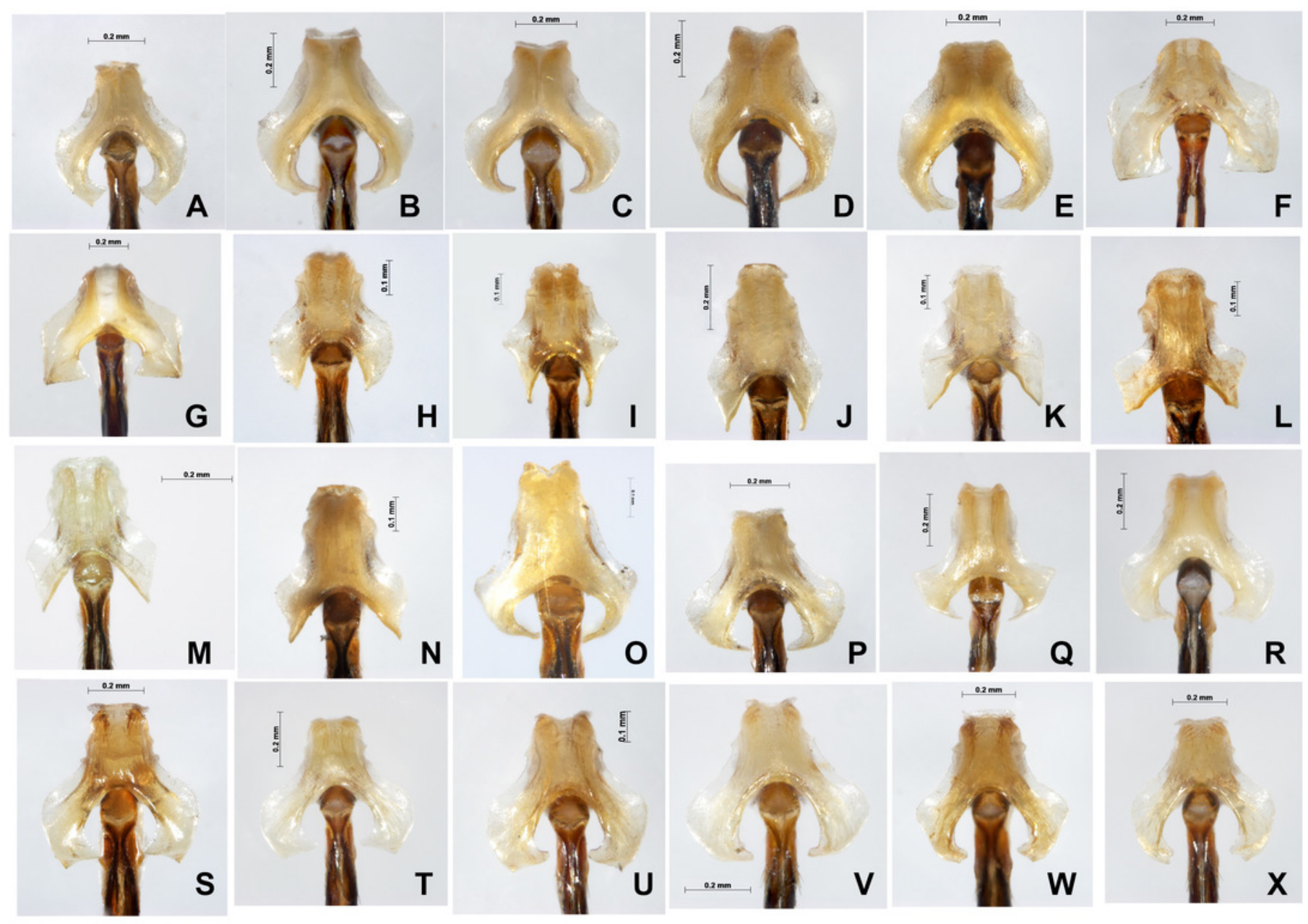




\section{Figure 9}

Hybridization between P. barbatum and P. melanotum in Changhu, Yunnan.

Fig. 9 Hybridization between $P$. barbatum and $P$. melanotum in Changhu, Yunnan. (A-H) Male caudal appendages and genital ligulae of $P$. barbatum; (I-P) Male caudal appendages and genital ligulae of hybrid individuals; (Q-X) Male caudal appendages and genital ligulae of $P$. melanotum. The most obvious characters showing the intermediate state of the hybrid are the shape of the end of the basal tooth on the cercus (a) and the distance between the two lateral teeth on the paraproct $(\mathrm{w})$. The general shape of genital ligulae also supports hybridization. All the individuals came from Changhu, the hybridization area.
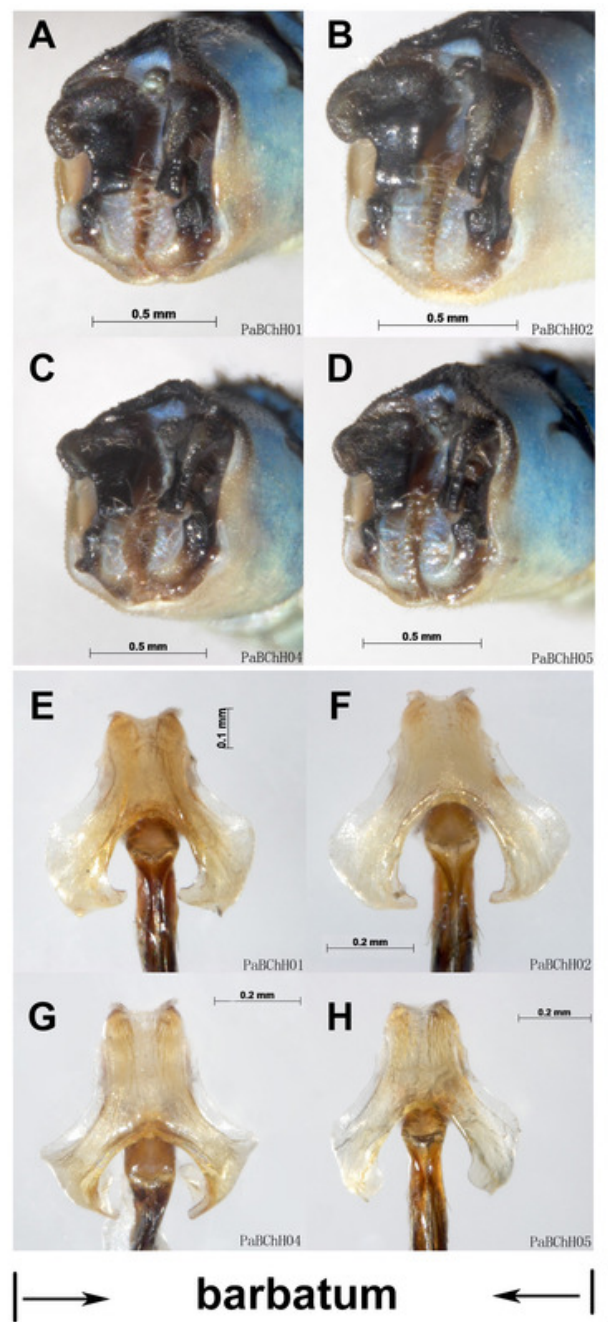
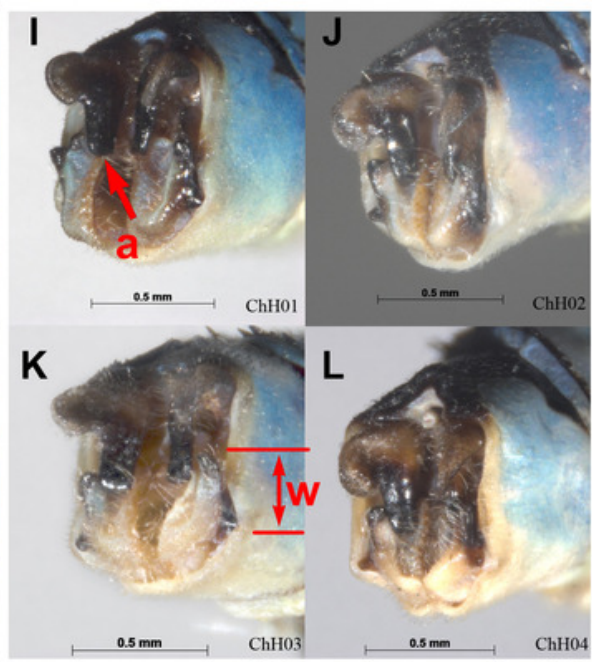

M

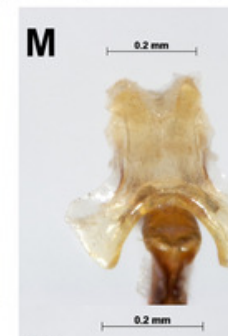

0

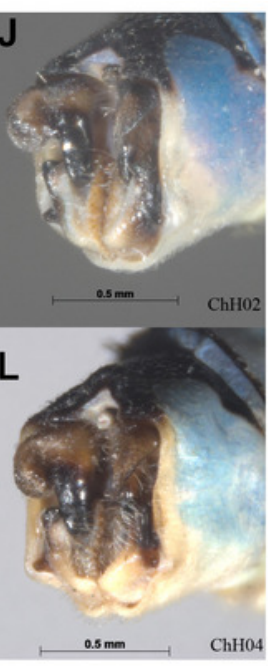

hybrid

P

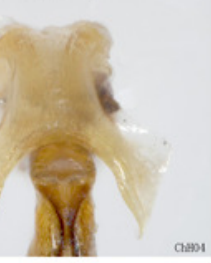

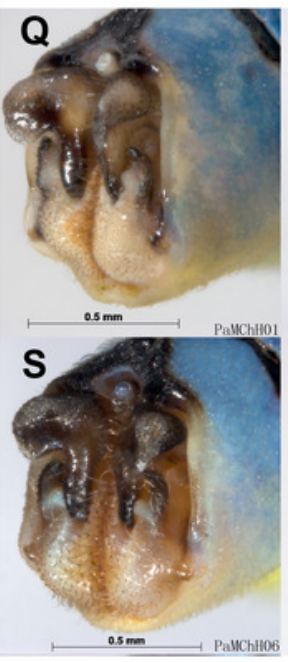
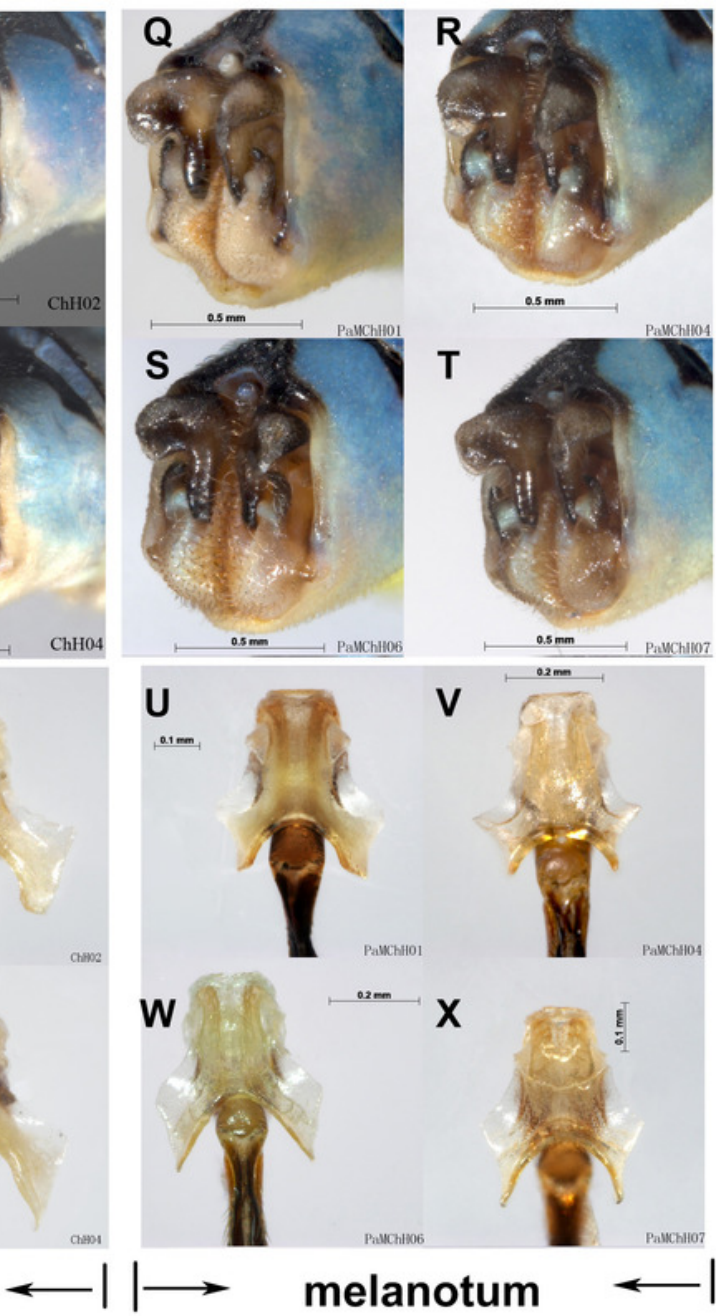

melanotum 


\section{Table 1 (on next page)}

Species delimitation result of General Mixed Yule Coalescent (GMYC) method

Table 1 Species delimitation result of General Mixed Yule Coalescent (GMYC) method 
1 Table 1 Species delimitation result of General Mixed Yule Coalescent (GMYC) method

\begin{tabular}{lcccc}
\hline Marker & LogLnull $^{\mathrm{a}}$ & LogLGMYC $^{\mathrm{b}}$ & Clusters $^{\mathrm{c}}$ & Entities $^{\mathrm{d}}$ \\
\hline COI & 1236.988 & $1275.555^{* * *}$ & $7(7-7)$ & $7(7-7)$ \\
ITS & 305.4786 & $308.7191^{*}$ & $9(3-14)$ & $12(3-24)$ \\
\hline
\end{tabular}

${ }^{a}$ The log-likelihood of the null model.

${ }^{\mathrm{b}}$ Maximum log-likelihood of GMYC model and the result of the likelihood ratio test $(* * * \mathrm{P}<0.001$,

$* * \mathrm{P}<0.01, * \mathrm{P}<0.05)$

${ }^{\mathrm{c}}$ Number of ML clusters (excluding singletons).

${ }^{\mathrm{d} N u m b e r}$ of ML entities (including singletons). 